Marija Miletić1, Miloš Stojanović1, Milan Jovanović2, Biljana Nedeljković-Beleslin ${ }^{1}$, Mirjana Stojkovićc ${ }^{1}$, Jasmina Ćirić ${ }^{1}$, Miloš Žarković ${ }^{1}$

\title{
PARATIROIDNI KARCINOM
}

Sažetak: Paratireoidni karcinom (PC) je neuobičajena maligna bolest, u literaturi je zabeleženo manje od 1.000 slučajeva, pošto ga je de Quervain 1904. godine opisao po prvi put kao nefunkcionalni metastatski karcinom. Sa procenjenom prevalencijom od $0,005 \%$ svih karcinoma PC je najređi endokrini karcinom $\mathrm{i}$ čini tek $0,5-5 \%$ svih slučajeva primarnog hiperparatireoidizma (PHPT). Patogeneza PC nije poznata. Etiologija PC-a je nepoznata i nema dokaza da PC nastaje transformacijom već postojećih paratiroidnih lezija. Aberantni profil ekspresije mikroRNK i metilacije nedavno identifikovanih putem PCR-a pružaju dokaze da su maligni oblici paratireoidne žlezde različiti od benignih lezija. PC može biti sporadičan ili biti deo genetskog sindroma. Sporadični PC je najčešće povezan sa izlaganjem spoljnoj radijaciji, a retko sa sekundarnim i tercijarnim HPT zbog hronične bubrežne insuficijencije. Takođe je zabeležena udruženost PC-a, sinhronog ili metahronog sa istorijom hiperplazije PT žlezda, paratiroidnog adenoma (PA) ili karcinoma štitne žlezde sa istovremenim PA. PC se obično manifestuje indolentnim, ali upornim kliničkim simptomima; pacijenti često pokazuju simptome i komplikacije teškog PHPT-a kao što su anksioznost, depresija, slabost, gubitak težine, bolesti kostiju i bubrega, bolovi u stomaku, mučnina, pankreatitis i peptični ulkus $[4,6,8,44]$. U prezentaciji 50\% pacijenata pokazuje manifestacije bubrežne i koštane patologije, uključujući osteopeniju, osteoporozu, osteofibrozu, osteitis fibrosa cistica, subperiostalnu resorpciju i patološke frakture. Bubrežna bolest se manifestuje uglavnom kao nefrolitijaza i bubrežna insuficijencija sa prevalencijom od 56, odnosno $84 \%$. Primećeno je da su nivoi kalcijuma u serumu često viši od 3,5 mmol / L (nasuprot $<2,8 \mathrm{mmol} / \mathrm{L}$ kod benigne bolesti), dok su nivoi PTH u serumu obično 3 do 10 puta veći od gornje normalne granice (benigna PT bolest može pokazivati umereniji porast), iako ne postoji

\footnotetext{
1 Marija Miletić, Klinika za Endokrinologiju, dijabetes i bolesti metabolizma, Klinički centar Srbije,drmariamiletic@gmail.com

2 Klinika za Endokrinologiju, dijabetes i bolesti metabolizma, Centar za endokrinu hirurgiju, Klinički centar Srbije
} 
dogovoreni prag nivoa PTH i nivoa kalcijuma u serumu za definisanje PT maligniteta. Kao i kod benigne bolesti, vizuelizacija je neophodna za lokalizaciju tumora, ali ne može pouzdano razlikovati benignu od maligne bolesti. Više metoda snimanja, najčešće kombinacija MIBI i ultrazvučnog pregleda vrata, povećava dijagnostičku osetljivost i tačnost. Neke ultrazvučne karakteristike mogu predvideti malignitet i pomoći u identifikovanju patoloških limfnih čvorova ili invazije na obližnje strukture: veličina $>3 \mathrm{~cm}$ treba da izazove sumnju na PC. Opisani su intraoperativni nalazi suspektni na PC. U većini serija, medijana maksimalnog prečnika PC je 3-3,5 cm $(<10 \%$ veći od $4 \mathrm{~cm})$, u poređenju sa približno $1,5 \mathrm{~cm}$ za PA. Izvešteno je da $21 \%$ karcinoma ima cističnu komponentu. Nijedan univerzalni sistem kliničkog i patološkog stadijuma za PC nije usvojen, jer ne postoji korelacija prečnika tumora ili statusa limfnih čvorova sa preživljavanjem, a bolest se veoma retko dijagnostikuje preoperativno ili čak intraoperativno. Schulte i saradnici su predložili sistem određivanja na osnovu dve klasifikacione šeme, diferencirane klasifikacije kao u okviru TNM klasifikacije i klasifikacije visokog rizika/ niskog rizika koja izgleda da pokazuje značajnu moć predviđanja za preživljavanje ili recidiv. Istorijski gledano, skoro 96\% pacijenata sa PC je lečeno hirurški, a hirurška intervencija je jedina efikasna terapija za kontrolu hiperkalcemije, kako u početnoj resekciji tako i u vreme ponovne pojave metastaza. Optimalno lečenje hiperkalcemije je važno pre operacije. Prikazana je pacijentkinja sa dugo neprepoznatim primarnim hiperparatiroidizmom uprkos ispoljavanju klasičnih znakova i simptoma oboljenja: bilateralne nefrokalkuloze, hipertenzije, pojačane žeđi, opstipacije, depresivnosti, bolova u lumbalnom delu kičme. Po prijemu u Kliniku za endokrinologiju i bolesti metabolizma učinjene su biohemijske analize: eGFR: $46 \mathrm{~mL} / \mathrm{min} / 1,73 \mathrm{~m}^{2}$, kalcijum: $3.34 \mathrm{mmol} / \mathrm{L}$ [2.15-2.65], kalcijum, jonizovani:1.89mmol/L [1.15-1.35], fosfor: 0.74 mmol/L [0.8-1.55], magnezijum: $0.72 \mathrm{mmol} / \mathrm{l}, \mathrm{PTH} 1276 \mathrm{ng} / \mathrm{l}$, vitamin D $14.2 \mathrm{nmol} / \mathrm{l}$. Nakon hitne terapije hiperkalcemije bisfosfonatima i.v., pacijentkinja je upućena na hirurško lečenje s obzirom na ispunjavanje operativnih kriterijuma. Učinjena je ekstrakcija gornje desne PT žlezde, a histopatološki nalaz je ukazao na paratiroidni karcinom.

Ključne reči: paratiroidni karcinom, primarni hiperparatiroidizam, hiperkalcemija

Summary: Parathyroid cancer (PC) is an uncommon malignant disease, with less than 1,000 cases reported in the literature since de Quervain first described it in 1904 as a non-functional metastatic cancer. With an estimated prevalence of $0.005 \%$ of all cancers, PC is the rarest endocrine cancer and accounts for only $0.5-5 \%$ of all cases of primary hyperparathyroidism (PHPT). The pathogenesis of PC is unknown. The etiology of PC is not clear and there is no evidence that PC is formed 
by the transformation of pre-existing parathyroid lesions. The aberrant profile of microRNA expression and methylation recently identified by PCR provides evidence that malignant forms of the parathyroid gland are different from benign lesions. PC may be sporadic or part of a genetic syndrome. Sporadic PC is most often associated with exposure to external radiation, and rarely with secondary and tertiary HPT due to chronic renal failure. The association of PC, synchronous or metachronous, with a history of PT gland hyperplasia, parathyroid adenoma (PA), or thyroid cancer with concomitant PA has also been reported. PC usually presents with indolent but persistent clinical symptoms; patients often show symptoms and complications of severe PHPT such as anxiety, depression, weakness, weight loss, bone and kidney disease, abdominal pain, nausea, pancreatitis, and peptic ulcer. In the investigation series, 50\% of patients show manifestations of renal and bone pathology, including osteopenia, osteoporosis, osteoofibrosis, osteitis fibrosa cystica, subperiosteal resorption and pathological fractures. Renal disease manifests mainly as nephrolithiasis and renal failure with a prevalence of 56 and $84 \%$, respectively. It has been observed that serum calcium levels are often higher than $3.5 \mathrm{mmol} / \mathrm{L}$ (as opposed to $<2.8 \mathrm{mmol} / \mathrm{L}$ in benign disease), while serum PTH levels are usually 3 to 10 times higher than the upper normal limit (benign PT). disease may show a more moderate increase), although there is no agreed threshold for PTH and serum calcium levels to define PT malignancy. As with benign disease, visualization is necessary for tumor localization, but it cannot reliably distinguish benign from malignant disease. Several imaging methods, most often a combination of MIBI and ultrasound examination of the neck, increase diagnostic sensitivity and accuracy. Some ultrasound features can predict malignancy and help identify pathological lymph nodes or invasion of nearby structures: a size $>3 \mathrm{~cm}$ should cause PC suspicion. Intraoperative findings suspected on PC have been described. In most series, the median maximum PC diameter is $3-3.5 \mathrm{~cm}(<10 \%$ greater than $4 \mathrm{~cm}$ ), compared to approximately $1.5 \mathrm{~cm}$ for PA. $21 \%$ of cancers have been reported to have a cystic component. No universal system of clinical and pathological stages for PC has been adopted, because there is no correlation between tumor diameter or lymph node status with survival, and the disease is very rarely diagnosed preoperatively or even intraoperatively. Schulte et al proposed a system of determination based on two classification schemes, a differentiated classification as within the TNM classification and a high-risk / low-risk classification that appears to show significant prediction power for survival or relapse. Historically, almost $96 \%$ of PC patients have been treated surgically, and surgery is the only effective therapy to control hypercalcemia, both at initial resection and at the time of metastasis recurrence. Optimal treatment of hypercalcemia is important before surgery. A patient with long 
unrecognized primary hyperparathyroidism despite the manifestation of classic signs and symptoms of the disease: bilateral nephrocalculosis, hypertension, increased thirst, constipation, depression, pain in the lumbar spine is presented. Upon admission to the Clinic for Endocrinology and Metabolic Diseases, biochemical analyzes were performed: eGFR: 46 $\mathrm{mL} / \mathrm{min} / 1.73 \mathrm{~m}$, calcium: 3.34mmol / L [2.15-2.65], calcium, ionized: $1.89 \mathrm{mmol} / \mathrm{L}$ [1.15- 1.35], phosphorus: $0.74 \mathrm{mmol} / \mathrm{L}$ [0.8 - 1.55], magnesium: $0.72 \mathrm{mmol} / \mathrm{l}$, PTH $1276 \mathrm{ng} /$, vitamin D $14.2 \mathrm{nmol} / 1$. After emergency therapy of hypercalcemia with bisphosphonates i.v., the patient was referred for surgical treatment due to the fulfillment of operative criteria. Extraction of the upper right PT gland was performed, and histopathological findings indicated parathyroid cancer.

Key words: parathyroid carcinoma, primary hyperparathyroidism, hypercalcemia

\section{Prikaz slučaja}

Pacijentkinja S.J., uzrasta 45 godina, žali se na malaksalost, bolove u lumbalnom delu kičme, anksioznost, depresivnost, pojačanu žeđ i opstipacije. Pacijentkinja je 3 godine ranije, nakon epizode renalne kolike, upućena na ESWL u Beograd koja tada nije učinjena iz tehničkih razloga. Nakon godinu dana ponovo ima renalnu koliku, sa oskudnim mokrenjem, uz mučninu, povraćanje, hospitalizovana u Zdravstvenom centru Užice u decembru 2019, kada je registrovana bilateralna kalkuloza bubrega, po prijemu plasiran JJ stent, uspostavljena uredna diureza i planirana endoskopska litotripsija levog bubrega koja je učinjena u novembru 2020, a u decembru plasirana JJ sonda levo. Tada je postavljena sumnja na primarni hiperparatiroidizam, učinjene laboratorijske analize PTH 1276.4, Ca 3.38 mmol/1, P 0.7 mmol/l, D vitamin 14.2. Učinjena MIBI scintigrafija paraštitastih žlezda u privatnom centru koja nije pokazala pojačano nakupljanje, upućena na lečenje u Kliniku za endokrinologiju. Na terapiji Euthyrox tbl. $25 \mathrm{mcg}$, Lasix tbl $40 \mathrm{mg}$ 1x1, Vivace tbl 1x1. Negira alergiju na lekove i hranu. Menopauza od 2019. Negira operacije osim uroloških. Porodična anamneza: Majka boluje od DM2. Negira ostala oboljenja od značaja za hereditet. Socijalno-epidemiološki podaci: Nepušač, ne konzumira alkohol, živi u komfornim uslovima.

Status praesens: Pacijentkinja svesna, orijentisana u vremenu, prostoru i prema licima, uredne OMG, TT 70.5kg, TV $168.5 \mathrm{~cm}$, BMI $24.8 \mathrm{~kg} / \mathrm{m}^{2}$, afebrilna, u miru eupnoična, acijanotična, bleđe prebojene kože i vidljivih sluznica, uredno hidrirana, bez periferne limfadenopatije, izraženih eflorescenci i znakova hemoragijskog sindroma. GLAVA: Uobičajene konfiguracije, palpatorno i perkutorno neosetljiva. Valeove tačke, mastoideusi i tragusi palpatorno bolno neosetljivi. Rime okuli sime- 
trične, bulbusi konjugovano i simetrično pokretni. Zenice kružne, adekvatne reakcije na svetlost i akomodaciju. Usne ružičaste. Sluznica usne duplje dobro prokrvljena, vlažna, jezik vlažan, neobložen, pokretan. Sluznica ždrela ružičasta. VRAT: cilindričan, aktivno i pasivno ograničeno pokretan, posebno na stranu. Vene vrata neupadljive, nad karotidama nema šuma. Štitasta žlezda uredne veličine, palpatorno bolno neosetljiva, pokretna pri gutanju, nečujan vaskularni šum nad žlezdom. Regionalne lgl se ne palpiraju. Grudni koš normosteničan, hemitoraksi simetrično respiratorno pokretni, auskultatorno normalan disajni šum, bez propratnog nalaza. Srčana radnja ritmična, fr 79/min, tonovi jasni, šumova nema. TA 135-90 mmHg. Prednji trbušni zid u ravni grudnog koša. Auskultatorno nema vaskularnih šumova, peristaltika čujna. Palpatorno, trbuh elastičan, pri dubokoj palpaciji bolno osetljiv u predelu donjeg desnog kvadranta. Jetra i slezina se ne palpiraju kao uvećane. Bubrežne lože bolno neosetljive na grubu sukusiju. Ekstremiteti su normalne veličine, simetrični, pokretni, bez deformiteta i venskih varikoziteta, bez otoka. Periferne arterijske pulsacije prisutne obostrano, simetrično. Muskulatura normalne trofike i tonusa, neosetljiva pri palpaciji, aktivnim i pasivnim pokretima. Biohemijske analize: Urea: 9.2mmol/L [2.5-7.5], kreatinin: 109 umol/L [45.0-84.0], eGFR: $46 \mathrm{~mL} / \mathrm{min} / 1,73 \mathrm{~m} 2$ kalcijum: $3.34 \mathrm{mmol} / \mathrm{L}$ [2.15-2.65], kalcijum, jonizovani: $1.89 \mathrm{mmol} / \mathrm{L}$ [1.15-1.35], fosfor: $0.74 \mathrm{mmol} / \mathrm{L}$ [0.8-1.55], magnezijum: $0.72 \mathrm{mmol} / 1$, PTH $1276 \mathrm{pg} / \mathrm{ml}$, vitamin D $14.2 \mathrm{nmol} / 1$, ostale analize uredne, alkalna fosfataza (ALP) u granici normale, tiroidni status na minimalnoj supstitutivnoj dozi uredan. Uzorak $24 \mathrm{~h}$ urina - kalcijum: $1.37 \mathrm{mmol} / \mathrm{L}$, $24 \mathrm{~h}$ urin - neorganski fosfat: $5.2 \mathrm{mmol} / \mathrm{L}$. Kateholamini (adrenalin, noradrenalin, dopamin) iz uzorka $24 \mathrm{~h}$ urina su u granici normale. Osteodenzitometrija nije mogla biti urađena iz tehničkih razloga. Radiografija srca i pluća: Desno infrahilarno naglašena bronhijalna šara. Ne vide se sigurni znaci infiltracije i konsolidacije u plućnom parenhimu. CF sinusi slobodni. Hemidijafragme uredno konturisane. Hilusne senke vaskularne uredne veličine. Srčano-sudovna senka u fiziološkim granicama. UZ pregled regije vrata: Štitasta žlezda je urednog položaja i veličine, homogene ehostrukture, urednog CD signala, bez fokalnih promena. Nema uvećanih regionalnih LN. Distalno i posteriorno desno vidi se hipo do heteroehogena promena promera $13 \times 14 \times 18 \mathrm{~mm}$, sa perifernom i diskretnom centralnom vaskularizacijom, intranodalno se vide mikrokalcifikati, promena je ddg UZ karakteritika maligne TU promene, ddg adenom gornje desne paraštitaste žlezde. Obe submandibularne i parotidne žlezde homogene ehostrukture, bez fokalnih promena, TIRADS DL 1 LL 1. Ehosonografija abdomena: Jetra je urednog položaja i veličine, homogene ehostrukture, bez fokalnih promena. Žučna kesa je presavijena, bez intralum. patološkog sadržaja. Žučni vodovi nisu dilatirani. Na spoju tela i repa pankreasa vidi se hipoehoegna promena koja će najpre odgovarati superponiranoj crevnoj vijuzi. Vaskularne strukture odgovaraju životnoj dobi. Slezina je urednog UZ nalaza. Desni bubreg KK dijametra $65 \mathrm{~mm}$, debljina korteksa $13 \mathrm{~mm}$, izmenjene kortikomedularne granice sa najmanje 2 kalku- 
lusa do $10 \mathrm{~mm}$. Levi bubreg kompenzatorno veći KK dijametra $11.6 \mathrm{~mm}$, debljina korteksa $19 \mathrm{~mm}$, jasna kortikomedularna granica, sa nekoliko hiperehogenih odjeka ddg manji kalkulusi, bez znakova hidronefroze. U projekciji nadbubrežnih loža ne vide se patološke promene. U abdomenu bez slobodne tečnosti i patoloških LN.

Po prijemu aplikovana Zolendronična kiselina $4 \mathrm{mg} \mathrm{u} 500 \mathrm{ml} \mathrm{NaCl} 0.9 \%$, uz Paracetamol 2 x $500 \mathrm{mg}$, nakon terapije Ca $3.03 \ldots .2 .98 \mathrm{mmol} / 1$, P $0.7 \mathrm{mmol} / \mathrm{l}$. Preoperativno Ca 2,50 mmmol/1, neorganski fosfat $0,8 \mathrm{mmol} / 1$, PTH 1276,4 ng/l. Operisana dana 25. 12. 2020, kada je učinjena gornja desna paratiroidektomija. Postoperativni tok protiče uredno. Rana zarasta per primam intentionem. Operativni nalaz: Po pripremi operativnog polja načinjen Koherov rez na bazi vrata. Razdvajanjem pothioidne muskulature duž bele linije pristupljeno visceralnoj loži vrata. Identifikovana uvećana gornja desna paratiroidna žlezda promera $30 \mathrm{~mm}$. Učinjena gornja desna paratiroidektomija. Donja leva PT normalnih karakteristika. Leva strana nije eksplorisana. NR identifikovan i sačuvan. Kontrola hemostaze. Rekonstrukcija rane po anatomskim slojevima. Makroskopski nalaz: 11033-36/20 Gornja desna paratireoidna žlezda: dva tkivna fragmenta, veći mase 1,5 gr dimenzija 15x12x10mm, lobularne konfiguracije, solidne rezne površine, svetlosmeđe boje. Manji fragment je mase $0,1 \mathrm{gr}$, dimenzija $7 \times 4 \times 4 \mathrm{~mm}$. Postoperativno kalcijum $1.89 \mathrm{mmol} / \mathrm{L}$, neorganski fosfat $1.15 \mathrm{mmol} / \mathrm{L}$, PTH $46 \ldots 44 \ldots 102 \mathrm{ng} / \mathrm{L}$. Terapija: Euthyrox a $25 \mathrm{mcg}, 1 \mathrm{x} 1$, svaki dan, ujutru, Caldeoss $1000 \mathrm{mg} / 880$ i. j. 2 x 1. Pristigao patohistološki nalaz: carcinoma gl. parathyreoideae. Imunohistohemija: u tu ćelijama pozitivni CK AE1/AE3, PTH, HegA, PGP 9,5, GALECTIN 3, CYCLIN d, BCL 2. Ki67: U $11 \%$ tu celija se vidi jedarna imunopozitivnost. MDCT toraksa: Medijastinalno nema patološke limfadenopatije. Pleuralni kavumi slobodni. Centriacinusni emfizem. Nema konsolidacije, infiltracije, niti kolapsa. Anterobazalno u DDL mikronodularna promena $2 \mathrm{~mm}$ (tstc - suviše mala za karakterizaciju). Na načinjenim presecima kroz gornji abdomen: "cyst like" promena u Vs jetre $2 \mathrm{~mm}$ (tstc); nadbubrezi voluminozni bez izdvajanja mass lezija; desni bubreg hipotrofičan sa kalkulozom. MDCT vrata i abdomena: Prikazane strukture u vratu su bez patoloških promena. Štitasta žlezda je normalne veličine i morfologije, homodenzna. Pojedinačne limfne žlezde nesignifikantnih dimenzija dijametra do $7 \mathrm{~mm}$ jugularno levo. Jetra je normalne veličine glatkih kontura, bez dilatacije intrahepatičnih žučnih puteva, sa cistom dijametra $4 \mathrm{~mm} \mathrm{u} \mathrm{V}$ segmentu. U desnom bubregu prisutan je kalkulus u čašici za gornji pol dijametra 8 $\mathrm{mm}$ (denziteta $1000 \mathrm{HU}$ ) i još jedan u čašici za donji pol dijametra $3 \mathrm{~mm}$. Takođe $u$ levom bubregu u gornjoj čašici kalkulus dijametra $5 \mathrm{~mm}$ i u donjoj jedan dijametra 3 $\mathrm{mm}$. Ostale prikazane strukture $u$ abdomenu su normalne prezentacije. Ne uočava se prisustvo uvećanih limfnih žlezda u abdomenu, kao ni prisustvo slobodne tečnosti. 99mTc MIBI Scintigrafija paraštitastih žlezda rađena je 20, 60 i 120 min nakon i.v. aplikacije radiofarmaka u AP projekciji. Na urađenim scintigramima prikazuje se hiperaktivna gornja leva paraštitasta žlezda. Pozitronska emisiona tomografija 
celog tela sa anatomskom lokalizacijom: (18F-FDG PET/CT celog tela) PET/CT snimanje celog tela (od baze lobanje do proksimalnih okrajaka femura) urađeno je $110 \mathrm{~min}$ posle i.v. ubrizgavanja $216 \mathrm{MBq}$ fluordeoksiglukoze obeležene fluorom-18 (18FDG). Ukupno utrošena radioaktivnost 18FDG-a je 384,42 MBq zbog gubitka MBq usled radioaktivnog raspada. Protokol snimanja: 1) CT topogram;2) niskodozni CT (40 mA), bez upotrebe kontrastnog sredstva; 3) 18FDG-PET. U evaluaciji nalaza korišćeni su fuzioni PET/CT preseci debljine $5 \mathrm{~mm}$ i nezavisni PET i CT preseci u sve tri ravni (transverzalni, koronalni i sagitalni), kao i obrtni 3D prikaz (MIP). Interpretacija nalaza je izvršena na syngovia serverima. Opis nalaza: U vratu bez patološke akumulacije radiofarmaka. U medijastinumu bez patološke akumulacije FDG. U plućnom parenhimu obostrano bez patološke akumulacije radiofarmaka. Uz veliku incizuru desnog plućnog krila se vidi mikronodus dijametra $2 \mathrm{~mm}$ i još jedan u superiornom segmentu donjeg režnja levog plućnog krila, takođe $2 \mathrm{~mm}$, premalih dimenzija za procenu metabolizma glukoze. Jetra sa difuznom nehomogenom akumulacijom radiofarmaka, uz izdvajanje par zona intenzivnije akumulacije: na granici sV/sVI jetre medijalno supkapsularno (SUVmax 5.8) dijametra $11 \mathrm{~mm}, \mathrm{u} \mathrm{sV}$ jetre dijametra $7 \mathrm{~mm}$ (SUVmax 4.8), i u sVI jetre dijametra 8mm (SUVmax 4.7), bez izdvajanja morfoloških promena na niskodoznom CT-u. Slezina i nadbubrežne žlezde bez patološke akumulacije FDG. Retroperitonealno i parailijačno bez patološke akumulacije radiofarmaka. Nehomogeno pojačana akumulacija radiofarmaka se uočava u nivou sternokostalnih spojeva, izrazitije levo, najpre degenerativne etiologije (SUVmax 3.8). U ostalim prikazanim kostima se ne izdvajaju fokalne zone patološke akumulacije. Zaključak: Opisane zone povišenog metabolizma glukoze u jetri zahtevaju precizniju morfološku evaluaciju. Savetuje se MR abdomena. Druge zone patološkog metabolizma glukoze se ne prikazuju. NMR abdomena: Jetra je uredne veličine, pravilnih kontura, bez fokalnih promena u parenhimu. Žučna kesa je uredne veličine, bez patološkog sadržaja u lumenu. Žučni putevi nisu prošireni. Portna vena je u regiji hepatoduodenalnog ligamenta, slobodnog lumena. Slezina, obe nadbubrežne žlezde, pankreas i bubrezi su uobičajenog oblika i veličine, uobičajenih MR tkivnih karakteristika. Uočavaju se mikrokalkulusi u oba bubrega sa početnom dilatacijom PK sistema obostrano. Na prikazanim presecima aorta je uredne širine lumena. Ne vidi se prisustvo slobodne tečnosti u peritonealnom prostoru, kao ni patološke proliferacije u peritoneumu. Ne vide se signifikantno uvećani parakavalni niti paraaortalni limfni čvorovi. U bazalnim delovima plućnog parenhima se ne vide patološke promene, pleuralni prostori su slobodni obostrano. Zaključak: 1. MR nalaz na parenhimskim organima gornjeg abdomena je uredan. U parenhimu jetre se ne uočavaju fokalne promene. 2. Mikrokalkulusi u oba bubrega uz početnu dilataciju PK sistema. Tokom anatomske i funkcionalne vizuelizacije elektroliti kontrolisani na treći dan, sve vreme normokalcemija, PTH $102 \ldots 125 \ldots 186$ ng/l. Obavljena je konsultacija endokrinog hirurga koji nije u ovom trenutku indikovao totalnu paratireoidektomiju, s obzirom na odrzavanje normokalcemije. Pacijentkinja je otpuštena, uz savet o kontroli $\mathrm{Ca}$, 
jonizovanog Ca, P, PTH i vitamina D na 4 nedelje. Terapija na otpustu: Vit D3 2000 IU 1x1, Euthyrox tbl $25 \mathrm{mcg}$, hidratacija, antihipertenzivna terapija.

\section{Diskusija}

Paratireoidni karcinom (PC) je neuobičajena maligna bolest, u literaturi je zabeleženo manje od 1000 slučajeva, pošto ga je de Quervain 1904. godine opisao po prvi put kao nefunkcionalni metastatski karcinom $[1,2,3,4,5,6]$. Sa procenjenom prevalencijom od $0,005 \%$ svih karcinoma $[7,8]$ PC je najređi endokrini karcinom i čini tek $0,5-5 \%$ svih slučajeva primarnog hiperparatireoidizma (PHPT) [6-12]. Patogeneza PC nije poznata. Može biti sporadična ili se ispoljiti u kontekstu genetskog sindroma kao kod hiperparatiroidizma/tumora vilice sindrom (HPT-JT), višestruke endokrine neoplazije tipa 1 (MEN1), tipa 2A (MEN2A) i porodičnog izolovanog hiperparatiroidizma (FIHP) [14-16]. PC predstavlja dijagnostički izazov zbog odsustva karakteristika koje bi omogućile definitivno razlikovanje malignog od benignog oboljenja. Zbog izuzetno retkog javljanja ne postoji opšti konsenzus o lečenju i praćenju.

Etiologija PC-a je nepoznata i nema dokaza da PC nastaje transformacijom već postojećih PT lezija [23]. Umesto toga, aberantni profil ekspresije mikroRNK i potpis metilacije nedavno identifikovani putem PCR-a pružaju dokaze da su maligni oblici paratireoidne žlezde različiti od benignih lezija [24]. PC može biti sporadičan ili biti deo genetskog sindroma [25]. Sporadični PC je povezan sa izlaganjem spoljnom zračenju [26, 27], a retko sa sekundarnim i tercijarnim HPT zbog hronične bubrežne insuficijencije [28-30]. Takođe je zabeležena udruženost PC-a, sinhronog ili metahronog sa istorijom hiperplazije PT žlezda, paratiroidnog adenoma (PA) ili karcinoma štitne žlezde sa istovremenim PA [21, 31, 32]. PC u kontekstu genetskog sindroma može se javiti kod 15\% osoba sa HPT-JT [16, 33, 34], kod 1\% pacijenata sa FIHP $[35,36]$, retko je prijavljeno kod MEN2A sindroma [37] i predstavlja $0,28-1 \%$ svih hirurški lečenih HPT u MEN 1 [38, 39]. Najčešće genetske anomalije povezane sa PC su inaktivacija somatskih mutacija gena parafibromina (CDC73 / HRPT2); druge abnormalnosti uključuju izmenjenu ekspresiju proteina p53 i retinoblastoma i gene za onkosupresor na hromozomu 13 [40-42]. Uoči potpune karakterizacije PC-a na molekularnom nivou, do petine slučajeva iz nedavne velike serije uzoraka pokazalo je promene onkogenog puta PI3K/AKT/mTOR, a otprilike u trećini je pokazana prekomerna ekspresija Ciclin D1 njegovom relativnom amplifikacijom gena CCND1 [43].

PC se obično manifestuje, indolentnim, ali upornim kliničkim simptomima; pacijenti često pokazuju simptome i komplikacije teškog PHPT-a kao što su anksioznost, depresija, slabost, gubitak težine, bolesti kostiju i bubrega, bolovi u stomaku, mučnina, pankreatitis i peptični ulkus $[4,6,8,44]$. U prezentaciji $50 \%$ pacijenata pokazuje manifestacije bubrežne i koštane patologije, uključujući osteopeniju, osteoporozu, 
osteofibrozu, osteitis fibrosa cistica, subperiostalnu resorpciju i patološke frakture (do $90 \%$ simptomatskih pacijenata) $[14,18,21,44]$. Bubrežna bolest se manifestuje uglavnom kao nefrolitijaza i bubrežna insuficijencija sa prevalencijom od 56, odnosno $84 \%$ [45]. Veoma sugestivan klinički znak je promuklost zbog paralyze n. laringeus recc. [46]. Simptomi koji se obično javljaju u poodmakloj fazi zbog kompresije / invazije susednih struktura [47-49]: masa vrata i/ili disfagija, promuklost ili otežano disanje $[7,22,50]$. Fizički pregled često može biti neupečatljiv, iako je opipljiva cervikalna masa opisana kod 30 do $76 \%$ pacijenata $[21,45,51,52]$. Potpuno asimptomatski PC zabeležen je kod 7 do čak $46 \%$ pacijenata [7, 45, 53, 54].

Laboratorijska ispitivanja: Primećeno je da su nivoi kalcijuma u serumu često viši od $3,5 \mathrm{mmol} / \mathrm{L}$ (nasuprot $<2,8 \mathrm{mmol} / \mathrm{L}$ kod benigne bolesti), dok su nivoi PTH u serumu obično 3 do 10 puta veći od gornje normalne granice (benigna PT bolest može pokazivati umereniji porast) $[26,45,50,55]$, iako ne postoji dogovoreni prag nivoa PTH i nivoa kalcijuma u serumu za definisanje PT maligniteta. Pokazalo se da je alkalna fosfataza znatno veća u PC u odnosu na benignu bolest, a nivoi $<300 \mathrm{IU} / \mathrm{L}$ verovatno neće biti povezani sa PC [54]. Nivoi humanog horionskog gonadotropina u serumu i urinu (zajedno sa njegovom hiperglikoziliranom izoformom) mogu biti abnormalno povišeni u PC, ali ne i u PA [56].

Kao i kod benigne bolesti, vizuelizacija je neophodna za lokalizaciju tumora, ali ne može pouzdano razlikovati benignu od maligne bolesti. Više metoda snimanja, najčešće kombinacija MIBI i ultrazvučnog pregleda vrata, povećava dijagnostičku osetljivost i tačnost $[5,14,57,58]$. Neke ultrazvučne karakteristike mogu predvideti malignitet i pomoći u identifikovanju patoloških limfnih čvorova ili invazije na obližnje strukture [59,60]: veličina $>3 \mathrm{~cm}$ treba da pokrene sumnju na PC [61]. Verovatnije je da će ultrazvucno biti opisani kao nehomogeni, hipoehogeni, sa lobuliranim/neograničenim marginama, degenerativnim promenama, intranodularnom kalcifikacijom, sumnjivom vaskularnošću, gustom kapsulom i lokalnom invazijom; naprotiv, PA se pojavljuju kao homogene, glatke i manje mase [61,62,63,64]. MIBI omogućava lokalizaciju, a time i razliku između eutopskog i ektopičnog paratiroidnog tkiva, kao i identifikaciju rekurentne bolesti $[46,58,65]$. CT i MRI mogu pružiti informacije o ekstenziji lezije, eventualnoj invaziji na okolne strukture, limfne čvorove ili udaljene metastaze [5,60]; CT obično pokazuje nisku osetljivost u otkrivanju paratiroidnog karcinoma [66], dok je MRI odgovarajući za studije mekih tkiva [67]. Dostupno je malo studija o upotrebi 18F-fluorodeoksiglukoze pozitronske emisione tomografije (FDG PET), čiji je cilj rana identifikacija metastaza/recidiva [67-70]. Citološka i histopatološka dijagnoza predstavljaju svojstven izazov [17, 20]. Ako se preoperativno sumnja na PC treba izbegavati FNA zbog rizika od širenja tumora duž iglenog puta, sa većim rizikom od recidiva [71,72]. 1973. godine Schantz i Castleman su prvi put objavili morfološke karakteristike koje definišu PC: vlaknaste trake raspoređene u trabekularni dizajn, kapsularna invazija $[73,74,75]$, vaskularna invazija i mitotska 
aktivnost [23]. Kapsularna i vaskularna invazija povezane su sa recidivima tumora i udaljenim metastazama i smatraju se jed,inim od patognomoničnih markera maligniteta $[76,77]$. Loša prognoza je takođe povezana sa obrascem DNK aneuploidnog tumora $[26,57,78]$. Histološke karakteristike nefunkcionalnog i funkcionalnog karcinoma su slične. Ovi tumori, koji uglavnom sadrže bistre ili oksifilne ćelije, veliki su i mogu se pogrešno dijagnostikovati kao karcinom štitaste žlezde ili timusa. Imunohistohemija može poboljšati dijagnostičku tačnost, kao što je takođe predloženo od Američkog udruženja endokrinih hirurga. Nefunkcionalni PC može pozitivno da se oboji za unutarćelijski PTH i hromogranin A, dok istovremeno ne prikazuje kalcitonin, tiroglobulin $\mathrm{i}$ faktor transkripcije štitaste žlezde [47]. Ki67 veći od 5\% sugeriše PC. Generalno, panel imunohistohemije je tačniji od upotrebe bilo kog pojedinačnog markera za dijagnozu karcinoma. Brojni onkogeni i onko-supresorski geni povezani su sa PC [79]. Somatsku mutaciju CDC73, gena za supresiju tumora povezanog sa ekspresijom parafibromina, nosi do 70\% PC [80]; takva mutacija se retko može naći u benignim sporadičnim PA $(0,8 \%)[29,81,82,83]$. Mutacije zametnih linija prisutne su u trećini slučajeva PC-a [84], što sugeriše HPT-JT sindrom u podgrupi pacijenata (mutacije zametnih linija gena CDC73 odgovorne su za HPT-JT, a povremeno i FIHP) [29, 33, 49, 81, 82, 85, $86,87,88,89,90,91,92]$. Prisustvo mutacije gena CDC73 sa negativnim bojenjem parafibromina, vrlo retko kod Pas-a, povećava verovatnoću maligniteta [93-102]. Drugi geni ili njihovi proteinski proizvodi, kao što su Rb, p53, BRCA2 (osetljivost na rak dojke) i PRAD1 (onkogen ciklin D1 / PA 1) [103-105] povezani su sa PC-om, mada nijedan od njih nije mogao dosledno i pouzdano da razlikuje benigne i maligne bolesti [105]. Anomalna ekspresija mikroRNK je takođe opisana u PC [106]. Ostali geni ili njihovi proteinski proizvodi, kao što su Rb, p53, BRCA2 (osetljivost na rak dojke) i PRAD1 (onkogen ciklin D1/PA 1) [103-105] povezani su sa PC-om, mada nijedan od njih nije mogao dosledno i pouzdano da razlikuje benigne i maligne bolesti [105]. Anomalna ekspresija mikroRNK je takođe opisana u PC [106].

Intraoperativna dijagnostika: Opisani su intraoperativni nalazi koji naglašavaju sumnju na PC. U većini serija, medijan amaksimalnog prečnika PC je 3-3,5 cm $(<10 \%$ veći od $4 \mathrm{~cm}$ ), u poređenju sa približno $1,5 \mathrm{~cm}$ za PA $[8,12,18,107]$. Boja se može kretati od sive do bele. Izvešteno je da $21 \%$ karcinoma ima cističnu komponentu [5, 31]. Ovi tumori su čvrsti, često pokazuju kameno-tvrdu konzistenciju, povremeno su lobulirani i obično okruženi gustom vlaknastom kapsulom. Oni inkorporiraju ili se pridržavaju susednih struktura, kao što su štitasta žlezda, mišići ramena, ipsilateralni RLN, jednjak i dušnik $[10,57,107,108]$. PA su umesto toga obično manji i mekani, crvenkasto-smeđe boje, okruglog ili ovalnog oblika [21, 107].

Nijedan univerzalni sistem kliničkog i patološkog stadijuma za PC nije usvojen, jer ne postoji korelacija prečnika tumora ili statusa limfnih čvorova sa preživljavanjem, a bolest se retko dijagnostikuje preoperativno ili čak intraoperativno $(8,11,27,109$, 110). Schulte i saradnici su predložili sistem određivanja na osnovu dve klasifikaci- 
one šeme, diferencirane klasifikacije kao u okviru TNM klasifikacije i klasifikacije visokog rizika/niskog rizika koja izgleda da pokazuje značajnu moć predviđanja za preživljavanje ili recidiv [111, 112]. Istorijski gledano, skoro $96 \%$ pacijenata sa PC je lečeno hirurški $[8,12]$, a hirurška intervencija je jedina efikasna terapija za kontrolu hiperkalcemije, kako u početnoj resekciji tako i u vreme ponovne pojave metastaza $[18,21,113]$. Optimalno lečenje hiperkalcemije je važno pre operacije [114]. U vreme prve operacije, potpuna resekcija sa mikroskopski negativnim marginama i netaknutom kapsulom tumora je izbor za postizanje najboljih šansi za izlečenje. Hirurške intervencije mogu se podeliti u dve glavne kategorije: interblok i lokalna ekscizija. Lokalna ekscizija uključuje perikapsularnu eksciziju samo pogođenog PT [112]. Međutim, većina autora se slaže da "en bloc" ekscizija u početnoj operaciji smanjuje potrebu za ponovljenom operacijom i poboljšava ishode preživljavanja; "en bloc" ekscizija sastoji se od resekcije tumora, ipsilateralne lobektomije štitaste žlezde i resekcije susednih cervikalnih mišića, paratrahealnog limfnog i alveolarnog tkiva i, ako je uključen, RLN segment $[13,79,110]$. Sveukupno, stopa lokalnog recidiva od $8 \%$ nakon resekcije "en bloc" upoređuje se sa 51\% nakon standardne paratiroidektomije [27]. Međutim, zabeleženo je da je samo 12,5\% pacijenata prošlo en blok resekciju u poređenju sa $78,5 \%$ kod kojih je učinjena paratiroidektomija, najverovatnije zbog toga što njihov PC nije identifikovan ni preoperativno, ponekad čak ni intraoperativno [12]. Ponovno istraživanje vrata, zajedno sa uklanjanjem tkiva koje okružuje uklonjeni PC, preporučuje se kada se dijagnoza postavi nakon početnog postupka [21].

Nema jasnih dokaza da provođenje profilaktičke CND ili bočne disekcije vrata može poboljšati preživljavanje $[8,12,14,31,115,116]$. S druge strane, CND je predložen pri prvom hirurškom pristupu kod svih pacijenata sa PC, na osnovu toga što je centralni odeljak bio uključen u do $10 \%$ slučajeva, a izostavljanje centralne i/ ili ipsilateralne disekcije jugularnog odeljenja moglo bi da nosi 1,5 do 2 puta veći rizik od petogodišnjeg recidiva i smrti [111]. Ekscizija limfnih čvorova - mimo one neophodne za eksciziju primarnog tumora u bloku - trenutno nije naznačena, osim ako čvorovi bolesti nisu klinički dokumentovani proširenim ili čvrstim čvorovima, posebno na VI, III i IV nivou [18]. Nakon resekcije PC-a, intraoperativni nivo PTH može značajno pasti, mada često ne tako brzo kao kod benigne bolesti; nijedan PTH ne može ukazivati na nepotpunu resekciju tumora ili istovremenu hiperplaziju višestrukih žlezda [117], ili čak na multiple karcinome [118]. Možda će biti potrebno istraživanje sve četiri paratireoidne žlezde, jer su karcinom u više žlezda i istovremeno prisustvo PC i PA dokumentovano u literaturi [119, 120].

Limfni čvorovi i udaljene metastaze u vreme postavljanja dijagnoze nisu česte, javljaju se u 1-6\% i 2-4\% [9, 11, 12, 26, 27, 45, 50, 53, 122]. Otprilike polovina pacijenata je doživela recidiv 2 do 5 godina nakon početne resekcije, obično sa polako rastućim nivoom kalcijuma i PTH u serumu u funkcionalnim PC-ima [22, 47, 110, 123]. Udaljene metastaze se javljaju kod oko $25 \%$ pacijenata $[26,124]$ tokom praćenja, 
iako je učestalost relapsa bila veća u poslednjim serijama [18]. Interval bez pojave metastatske bolesti može biti i do 20 godina [94, 110, 124], sa najčešćim mestima u plućima (40\%), jetri (10\%) i, vrlo retko, u kostima, pleuri, perikardu i pankreasu $[20,21]$. Klinički tok je obično indolentan, a neki pacijenti prežive godinama čak i nakon dijagnoze metastatske bolesti. Napredak bolesti obično je obeležen kliničkim manifestacijama hiperkalcemije i s tim povezanim komplikacijama [21]. U nekim slučajevima prvi pokazatelj maligniteta tumora može biti ponavljajuća ili metastatska bolest u prethodnoj paratiroidektomiji zbog hiperkalcemije [53]. Rekurenca je obično regionalna, čini približno dve trećine recidiva [26] i često ga je teško otkriti, jer može biti mali, multifokalni ili izrasti u ožiljku iz prethodne operacije. Približno polovina pacijenata sa recidivom takođe ima udaljene metastaze [124].

\section{Literatura:}

1. Quervain Fd. Parastruma maligna aberrata. Deutsche Zeitschrift Fuer Chirurgie. 1904; 100: 334-52.

2. Mohebati A, S. A., Shah J, Parathyroid carcinoma: challenges in diagnosis and treatment. Hematol Oncol Clin North Am, 2012; 26: 1221-1238.

3. Beus KS, Stack BC Jr. Parathyroid carcinoma. Otolaryngol Clin N Am. 2004; 37(4): $845-54 \mathrm{x}$.

4. Dudney WC, Bodenner D, Stack BC Jr. Parathyroid carcinoma. Otolaryngol Clin N Am. 2010; 43(2): 441-53 xi.

5. Wei $\mathrm{CH}$, Harari A. Parathyroid carcinoma: update and guidelines for management. Curr Treat Options in Oncol. 2012; 13(1): 11-23.

6. Givi B, Shah JP. Parathyroid carcinoma. Clin Oncol (R Coll Radiol). 2010; 22(6): 498-507.

7. Sharretts JM, Kebebew E, Simonds WF. Parathyroid cancer. Semin Oncol. 2010; 37(6): $580-90$.

8. Hundahl SA, et al. Two hundred eighty-six cases of parathyroid carcinoma treated in the U.S. between 1985-1995: a National Cancer Data Base Report. The American College of Surgeons Commission on Cancer and the American Cancer Society. Cancer. 1999; 86(3): 538-44.

9. Marcocci C, et al. Parathyroid carcinoma. J Bone Miner Res. 2008; 23(12): 1869-80.

10. Holmes EC, Morton DL, Ketcham AS. Parathyroid carcinoma: a collective review. Ann Surg. 1969; 169(4): 631-40.

11. Fujimoto $Y$, et al. Surgical treatment of ten cases of parathyroid carcinoma: importance of an initial en bloc tumor resection. World J Surg. 1984; 8(3): 392-400.

12. Lee PK, et al. Trends in the incidence and treatment of parathyroid cancer in the United States. Cancer. 2007; 109(9): 1736-41.

13. Cohn K, et al. Parathyroid carcinoma: The Lahey clinic experience. Surgery. 1985; 98(6): 1095-100. 
14. Kebebew E. Parathyroid carcinoma. Curr Treat Options in Oncol. 2001; 2(4): 347-54.

15. Kebebew E. Parathyroid carcinoma, a rare but important disorder for endocrinologists, primary care physicians, and endocrine surgeons. Thyroid. 2008; 18(4): 385-6.

16. Sharretts JM, Simonds WF. Clinical and molecular genetics of parathyroid neoplasms. Best Pract Res Clin Endocrinol Metab. 2010; 24(3): 491-502.

17. Di Meo G, et al. Parathyroid carcinoma in multiple endocrine neoplasm type 1 syndrome: case report and systematic literature review. Clin Exp Med. 2018: 1-9.

18. Rahbari R, E K, VT DV Jr, Lawrence TS, Rosenberg SA. Parathyroid tumors, in Cancer: Principles and Practice of Oncology. Philadelphia: Wolters Kluwer Health/Lippincott Williams \& Wilkins, c 2011; 1473-9.

19. Fraker DL. Update on the management of parathyroid tumors. Curr Opin Oncol. 2000; 12(1): 41-8.

20. Favia G, et al. Parathyroid carcinoma: sixteen new cases and suggestions for correct management. World J Surg. 1998;22(12):1225-30.

21. Shane E. Clinical review 122: parathyroid carcinoma. J Clin Endocrinol Metab. 2001; 86(2): 485-93.

22. Wilkins BJ, Lewis JS Jr. Non-functional parathyroid carcinoma: a review of the literature and report of a case requiring extensive surgery. Head Neck Pathol. 2009; 3(2): 140-9.

23. Schantz A, Castleman B. Parathyroid carcinoma. A study of 70 cases. Cancer. 1973; 31(3): 600-5.

24. Verdelli C, Corbetta S. Epigenetic alterations in parathyroid cancers. Int J Mol Sci. 2017; 18(2): 310 .

25. Marx SJ, et al. Hyperparathyroidism in hereditary syndromes: special expressions and special managements. J Bone Miner Res. 2002; 17(Suppl 2): N37-43.

26. Obara T, Fujimoto Y. Diagnosis and treatment of patients with parathyroid carcinoma: an update and review. World J Surg. 1991; 15(6): 738-44.

27. Koea JB, Shaw JH. Parathyroid cancer: biology and management. Surg Oncol. 1999; 8(3): 155-65.

28. Khan MW, et al. Parathyroid carcinoma in secondary and tertiary hyperparathyroidism. J Am Coll Surg. 2004; 199(2): 312-9.

29. Carpten JD, et al. HRPT2, encoding parafibromin, is mutated in hyperparathyroidism-jaw tumor syndrome. Nat Genet. 2002; 32(4): 676-80.

30. DeLellis RA. Parathyroid tumors and related disorders. Mod Pathol. 2011; 24(Suppl 2): S78-93.

31. Harari A, et al. Parathyroid carcinoma: a 43-year outcome and survival analysis. J Clin Endocrinol Metab. 2011;96(12):3679-86.

32. Goldfarb M, et al. Synchronous parathyroid carcinoma, parathyroid adenoma, and papillary thyroid carcinoma in a patient with severe and long-standing hyperparathyroidism. Endocr Pract. 2009; 15(5): 463-8.

33. Newey PJ, et al. Cell division cycle protein 73 homolog (CDC73) mutations in the hyperparathyroidism-jaw tumor syndrome (HPT-JT) and parathyroid tumors. Hum Mutat. 2010; 31(3): 295-307. 
34. Bradley KJ, et al. Uterine tumours are a phenotypic manifestation of the hyperparathyroidism-jaw tumour syndrome. J Intern Med. 2005; 257(1): 18-26.

35. Wassif WS, et al. Familial isolated hyperparathyroidism: a distinct genetic entity with an increased risk of parathyroid cancer. J Clin Endocrinol Metab. 1993; 77(6): 1485-9.

36. Simonds WF, et al. Familial isolated hyperparathyroidism: clinical and genetic characteristics of 36 kindreds. Medicine (Baltimore). 2002; 81(1): 1-26.

37. Jenkins PJ, et al. Metastatic parathyroid carcinoma in the MEN2A syndrome. Clin Endocrinol. 1997; 47(6): 747-51.

38. del Pozo C, et al. Parathyroid carcinoma in multiple endocrine neoplasia type 1. Case report and review of the literature. Hormones (Athens). 2011; 10(4): 326-31.

39. Singh Ospina N, et al. Prevalence of parathyroid carcinoma in 348 patients with multiple endocrine neoplasia type 1 - case report and review of the literature. Clin Endocrinol. 2014.

40. Cryns VL, et al. Loss of the retinoblastoma tumor-suppressor gene in parathyroid carcinoma. N Engl J Med. 1994; 330(11): 757-61.

41. Shattuck TM, et al. Mutational analyses of RB and BRCA2 as candidate tumour suppressor genes in parathyroid carcinoma. Clin Endocrinol. 2003; 59(2): 180-9.

42. Cryns VL, et al. p53 abnormalities in human parathyroid carcinoma. J Clin Endocrinol Metab. 1994; 78(6): 1320-4.

43. Pandya $\mathrm{C}$, et al. Genomic profiling reveals mutational landscape in parathyroid carcinomas. JCI insight. 2017; 2(6).

44. Levin KE, Galante M, Clark $\mathrm{OH}$. Parathyroid carcinoma versus parathyroid adenoma in patients with profound hypercalcemia. Surgery. 1987; 101(6): 649-60.

45. Wynne AG, et al. Parathyroid carcinoma: clinical and pathologic features in 43 patients. Medicine (Baltimore). 1992; 71(4): 197-205.

46. Duan K, Mete O, Carcinoma P. Diagnosis and clinical implications. Turk Patoloji Derg. 2015;31(Suppl 1): 80-97.

47. Gao WC, et al. Nonfunctional parathyroid carcinoma. J Cancer Res Clin Oncol. 2010; 136(7): 969-74.

48. Fernandez-Ranvier GG, et al. Nonfunctioning parathyroid carcinoma: case report and review of literature. Endocr Pract. 2007; 13(7): 750-7.

49. Guarnieri V, et al. Diagnosis of parathyroid tumors in familial isolated hyperparathyroidism with HRPT2 mutation: implications for cancer surveillance. J Clin Endocrinol Metab. 2006; 91(8): 2827-32.

50. Fernandez-Ranvier GG, et al. Parathyroid carcinoma, atypical parathyroid adenoma, or parathyromatosis? Cancer. 2007; 110(2): 255-64.

51. Chow E, et al. Parathyroid carcinoma--the Princess Margaret hospital experience. Int J Radiat Oncol Biol Phys. 1998; 41(3): 569-72.

52. August DA, et al. Parathyroid carcinoma: the relationship of nuclear DNA content to clinical outcome. Surgery. 1993; 113(3): 290-6.

53. Busaidy NL, et al. Parathyroid carcinoma: a 22-year experience. Head Neck. 2004; 26(8): 716-26. 
54. Bae JH, et al. Preoperative predictive factors for parathyroid carcinoma in patients with primary hyperparathyroidism. J Korean Med Sci. 2012; 27(8): 890-5.

55. Shane E, Bilezikian JP. Parathyroid carcinoma: a review of 62 patients. Endocr Rev. 1982; 3(2): 218-26.

56. Stock JL, et al. Human chorionic gonadotropin subunit measurement in primary hyperparathyroidism. J Clin Endocrinol Metab. 1982; 54(1): 57-63.

57. K, S., Parathyroid Carcinoma, in Textbook of endocrine surgery, D.Q. Clark OH, Kebebew E, Editor. 2005, Elsevier Saunders: Philadelphia. p. 549-554.

58. Patel CN, et al. Clinical utility of ultrasound and 99mTc sestamibi SPECT/CT for preoperative localization of parathyroid adenoma in patients with primary hyperparathyroidism. Clin Radiol. 2010; 65(4): 278-87.

59. Thompson LD. Parathyroid carcinoma. Ear Nose Throat J. 2009; 88(1): 722-4.

60. Al-Kurd A, Mekel M, Mazeh H. Parathyroid carcinoma. Surg Oncol. 2014; 23(2): 107-14.

61. Kwon JH, et al. Neck ultrasonography as preoperative localization of primary hyperparathyroidism with an additional role of detecting thyroid malignancy. Eur J Radiol. 2013; 82(1): e17-21.

62. Hara H, et al. Ultrasonographic features of parathyroid carcinoma. Endocr J. 2001; 48(2): 213-7.

63. Tamler R, et al. Parathyroid carcinoma: ultrasonographic and histologic features. Thyroid. 2005; 15(7): 744-5.

64. Nam M, Jeong HS, Shin JH. Differentiation of parathyroid carcinoma and adenoma by preoperative ultrasonography. Acta Radiol. 2017; 58(6): 670-5.

65. Al-Sobhi S, Ashari LH, Ingemansson S. Detection of metastatic parathyroid carcinoma with Tc-99m sestamibi imaging. Clin Nucl Med. 1999; 24(1): 21-3.

66. Kassahun WT, Jonas S. Focus on parathyroid carcinoma. Int J Surg. 2011; 9(1): 13-9

67. Evangelista L, et al. FDG-PET/CT and parathyroid carcinoma: review of literature and illustrative case series. World J Clin Oncol. 2011; 2(10): 348-54.

68. Gardner CJ, et al. Localization of metastatic parathyroid carcinoma by $18 \mathrm{~F}$ FDG PET scanning. J Clin Endocrinol Metab. 2010; 95(11): 4844-5.

69. Neumann DR, et al. Preoperative imaging of parathyroid carcinoma by positron emission tomography. Ann Otol Rhinol Laryngol. 1994; 103(9): 741-5.

70. Arslan N, Rydzewski B. Detection of a recurrent parathyroid carcinoma with FDG positron emission tomography. Clin Nucl Med. 2002;27(3):221-2.

71. Agarwal $\mathrm{G}$, et al. Implantation of parathyroid carcinoma along fine needle aspiration track. Langenbeck's Arch Surg. 2006; 391(6): 623-6.

72. Spinelli C, et al. Cutaneous spreading of parathyroid carcinoma after fine needle aspiration cytology. J Endocrinol Investig. 2000; 23(4): 255-7.

73. Delellis RA. Challenging lesions in the differential diagnosis of endocrine tumors: parathyroid carcinoma. Endocr Pathol. 2008; 19(4): 221-5.

74. Apel RL, L.V., Asa SL The parathyroid glands, in Endocrine pathology. 2002, New York : Churchill Livingstone, c2002: Philadelphia - United States. 103-147.

75. DeLellis RA. Parathyroid carcinoma: an overview. Adv Anat Pathol. 2005; 12(2): 53-61. 
76. Smith JF, Coombs RR. Histological diagnosis of carcinoma of the parathyroid gland. J Clin Pathol. 1984; 37(12): 1370-8.

77. Bondenson L, G.L., DeLellis RA, Lloyd R, Akerstrom G, Larsson C, Arnold A, Eng C, Shane E, Bilezikian JP. In: DeLellis RA, Lloyd RV, Heitz PU, Eng C. Parathyroid Carcinoma, in Pathology and genetics of tumours of endocrine organs. WHO classification tumours of endocrine organs. 2004, Lyon: IARC Press, 2004: Lyon - France. 124-127.

78. Levin KE, et al. Deoxyribonucleic acid cytometry helps identify parathyroid carcinomas. J Clin Endocrinol Metab. 1988; 67(4): 779-84.

79. Clayman GL, et al. Parathyroid carcinoma: evaluation and interdisciplinary management. Cancer. 2004; 100(5): 900-5.

80. Woodard GE, et al. Parafibromin, product of the hyperparathyroidism-jaw tumor syndrome gene HRPT2, regulates cyclin D1/PRAD1 expression. Oncogene. 2005; 24(7): 1272-6.

81. Howell VM, et al. HRPT2 mutations are associated with malignancy in sporadic parathyroid tumours. J Med Genet. 2003; 40(9): 657-63.

82. Cetani $\mathrm{F}$, et al. A reappraisal of the $\mathrm{Rb} 1$ gene abnormalities in the diagnosis of parathyroid cancer. Clin Endocrinol. 2004; 60(1): 99-106.

83. Krebs LJ, Shattuck TM, Arnold A. HRPT2 mutational analysis of typical sporadic parathyroid adenomas. J Clin Endocrinol Metab. 2005; 90(9): 5015-7.

84. Shattuck TM, et al. Somatic and germ-line mutations of the HRPT2 gene in sporadic parathyroid carcinoma. N Engl J Med. 2003; 349(18): 1722-9.

85. Cetani F, et al. Genetic analyses of the HRPT2 gene in primary hyperparathyroidism: germline and somatic mutations in familial and sporadic parathyroid tumors. J Clin Endocrinol Metab. 2004; 89(11): 5583-91.

86. Simonds WF, et al. Familial isolated hyperparathyroidism is rarely caused by germline mutation in HRPT2, the gene for the hyperparathyroidism-jaw tumor syndrome. J Clin Endocrinol Metab. 2004; 89(1): 96-102.

87. Warner J, et al. Genetic testing in familial isolated hyperparathyroidism: unexpected results and their implications. J Med Genet. 2004; 41(3): 155-60.

88. Villablanca A, et al. Germline and de novo mutations in the HRPT2 tumour suppressor gene in familial isolated hyperparathyroidism (FIHP). J Med Genet. 2004; 41(3): e32.

89. Bradley KJ, et al. Parafibromin mutations in hereditary hyperparathyroidism syndromes and parathyroid tumours. Clin Endocrinol. 2006; 64(3): 299-306.

90. Mizusawa N, et al. Genetic analyses in patients with familial isolated hyperparathyroidism and hyperparathyroidism-jaw tumour syndrome. Clin Endocrinol. 2006; 65(1): 9-16.

91. Kelly TG, et al. Surveillance for early detection of aggressive parathyroid disease: carcinoma and atypical adenoma in familial isolated hyperparathyroidism associated with a germline HRPT2 mutation. J Bone Miner Res. 2006; 21(10): 1666-71.

92. Korpi-Hyovalti E, et al. CDC73 intragenic deletion in familial primary hyperparathyroidism associated with parathyroid carcinoma. J Clin Endocrinol Metab. 2014; 99(9): 3044-8.

93. Cetani F, et al. Should parafibromin staining replace HRTP2 gene analysis as an additional tool for histologic diagnosis of parathyroid carcinoma? Eur J Endocrinol. 2007; 156(5): 547-54. 
94. Guarnieri V, et al. CDC73 mutations and parafibromin immunohistochemistry in parathyroid tumors: clinical correlations in a single -Centre patient cohort. Cell Oncol (Dordr). 2012; 35(6): 411-22.

95. Wang O, et al. Novel HRPT2/CDC73 gene mutations and loss of expression of parafibromin in Chinese patients with clinically sporadic parathyroid carcinomas. PLoS One. 2012; 7(9): e 45567.

96. Tan $\mathrm{MH}$, et al. Loss of parafibromin immunoreactivity is a distinguishing feature of parathyroid carcinoma. Clin Cancer Res. 2004; 10(19): 6629-37.

97. Juhlin C, et al. Loss of parafibromin expression in a subset of parathyroid adenomas. Endocr Relat Cancer. 2006; 13(2): 509-23.

98. Juhlin CC, et al. Parafibromin immunoreactivity: its use as an additional diagnostic marker for parathyroid tumor classification. Endocr Relat Cancer. 2007; 14(2): 501-12.

99. Howell VM, et al. Accuracy of combined protein gene product 9.5 and parafibromin markers for immunohistochemical diagnosis of parathyroid carcinoma. J Clin Endocrinol Metab. 2009; 94(2): 434-41.

100. Kim HK, et al. Parafibromin immunohistochemical staining to differentiate parathyroid carcinoma from parathyroid adenoma. Head Neck. 2012; 34(2): 201-6.

101. Witteveen JE, et al. Downregulation of CASR expression and global loss of parafibromin staining are strong negative determinants of prognosis in parathyroid carcinoma. Mod Pathol. 2011; 24(5): 688-97.

102. Gill AJ, et al. Loss of nuclear expression of parafibromin distinguishes parathyroid carcinomas and hyperparathyroidism-jaw tumor (HPT-JT) syndrome-related adenomas from sporadic parathyroid adenomas and hyperplasias. Am J Surg Pathol. 2006; 30(9): 1140-9.

103. Cetani F, et al. Molecular pathogenesis of primary hyperparathyroidism. J Endocrinol Investig. 2011; 34(7 Suppl): 35-9.

104. Kebebew E, et al. Localization and reoperation results for persistent and recurrent parathyroid carcinoma. Arch Surg. 2001; 136(8): 878-85.

105. Fernandez-Ranvier GG, et al. Defining a molecular phenotype for benign and malignant parathyroid tumors. Cancer. 2009; 115(2): 334-44.

106. Verdelli C, et al. MicroRNA deregulation in parathyroid tumours suggests an embryonic signature. J Endocrinol Investig. 2015; 38(4): 383-8.

107. Clark O. Parathyroid Carcinoma. In: Doherty GM, L W, editors. Current surgical diagnosis and treatment. Michigan: McGraw-Hill Medical; 2006. p. 284-93.

108. Rodgers SE, Perrier ND. Parathyroid carcinoma. Curr Opin Oncol. 2006; 18(1): 16-22.

109. Hakaim AG, Esselstyn CB Jr. Parathyroid carcinoma: 50-year experience at the Cleveland Clinic Foundation. Cleve Clin J Med. 1993; 60(4): 331-5.

110. Sandelin K, et al. Prognostic factors in parathyroid cancer: a review of 95 cases. World J Surg. 1992; 16(4): 724-31.

111. Talat N, Schulte KM. Clinical presentation, staging and long-term evolution of parathyroid cancer. Ann Surg Oncol. 2010; 17(8): 2156-74.

112. Schulte KM, et al. Classification of parathyroid cancer. Ann Surg Oncol. 2012; 19(8): 2620-8. 
113. Iacobone M, Lumachi F, Favia G. Up-to-date on parathyroid carcinoma: analysis of an experience of 19 cases. J Surg Oncol. 2004; 88(4): 223-8.

114. Biloš LSK, Pavlović D, Kellar F. Parathyroid carcinoma: a diagnostic and treatment challenge. Endocr Oncol Metab. 2016; 10(2): 194-205.

115. Hsu KT, et al. Is central lymph node dissection necessary for parathyroid carcinoma? Surgery. 2014; 156(6): 1336-41 discussion 1341.

116. Enomoto K, et al. The surgical strategy and the molecular analysis of patients with parathyroid cancer. World J Surg. 2010; 34(11): 2604-10.

117. Oh MY, et al. Concurrent parathyroid carcinoma and hyperplasia in hyperparathyroidism. Korean J Intern Med. 2012;27(3): 356-9.

118. Falvo L, et al. Bilateral synchronous parathyroid carcinoma in a patient on long-term hemodialysis: presentation of a rare clinical case and review literature. Int Surg. 2005; 90(1): 18-22.

119. Sahasranam $P$, et al. Multiglandular parathyroid carcinoma: a case report and brief review. South Med J. 2007; 100(8): 841-4.

120. Kameyama K, Takami H. Double parathyroid carcinoma. Endocr J. 2003; 50(4): 477-9.

121. Hoelting T, et al. Surgical treatment of parathyroid carcinoma (review). Oncol Rep. 2001; 8(4): 931-4.

122. Schulte KM, Talat N. Diagnosis and management of parathyroid cancer. Nat Rev Endocrinol. 2012; 8(10): 612-22.

123. Anderson BJ, et al. Parathyroid carcinoma: features and difficulties in diagnosis and management. Surgery. 1983; 94(6): 906-15.

124. Sandelin K, Tullgren O, Farnebo LO. Clinical course of metastatic parathyroid cancer. World J Surg. 1994; 18(4): 594-8; discussion 599. 